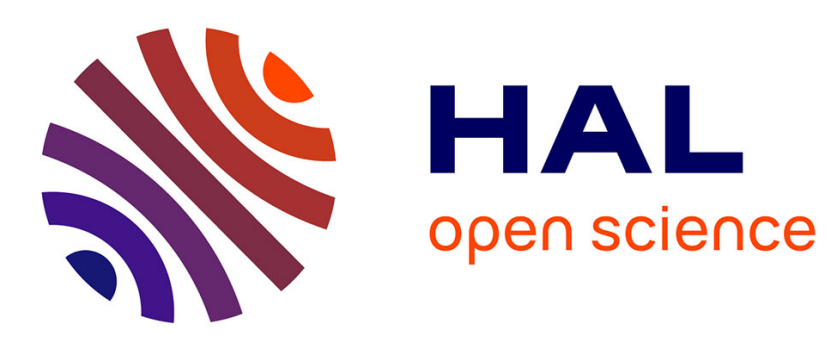

\title{
Photo response of the EL2 absorption band and of the As+Ga ESR signal in GaAs
}

\author{
B. Dischler, U. Kaufmann
}

\section{To cite this version:}

B. Dischler, U. Kaufmann. Photo response of the EL2 absorption band and of the As+Ga ESR signal in GaAs. Revue de Physique Appliquée, 1988, 23 (5), pp.779-791. 10.1051/rphysap:01988002305077900 . jpa-00245882

\section{HAL Id: jpa-00245882 https://hal.science/jpa-00245882}

Submitted on 1 Jan 1988

HAL is a multi-disciplinary open access archive for the deposit and dissemination of scientific research documents, whether they are published or not. The documents may come from teaching and research institutions in France or abroad, or from public or private research centers.
L'archive ouverte pluridisciplinaire HAL, est destinée au dépôt et à la diffusion de documents scientifiques de niveau recherche, publiés ou non, émanant des établissements d'enseignement et de recherche français ou étrangers, des laboratoires publics ou privés. 


\title{
Photo response of the EL2 absorption band and of the $\operatorname{As}_{\mathbf{G a}}^{+}$ESR signal in GaAs
}

\author{
B. Dischler and U. Kaufmann \\ Fraunhofer-Institut für Angewandte Festkörperphysik, Eckerstr. 4, D-7800 Freiburg, F.R.G.
}

(Reçu le 15 juillet 1987, accepté le 23 octobre 1987)

\begin{abstract}
Résumé. - La réponse optique de la bande d'absorption de EL2 et du spectre paramagnétique du $\mathrm{As}_{\mathrm{Ga}}^{+}$dans GaAs sont décrites et comparées avec les propriétés optiques du défaut EL2, déterminé à partir des mesures de photocapacitance. Nous avons analysé les variations en intensité de la bande d'absorption induit par une excitation optique secondaire en termes de sections efficaces de capture optique de EL2 ; la régénération thermique de cette bande est également discutée. L'excitation optique avec une énergie inférieure à la bande interdite induit aussi des changements dans le spectre d'absorption en dessous de $0.75 \mathrm{eV}$. Ceci est attribué à la présence de porteurs libres créés optiquement. Leur génération est corrélée à la présence de EL2. La comparaison de ces résultats avec ceux du défaut $\mathrm{As}_{\mathrm{Ga}}^{+}$montre que les deux défauts possèdent les mêmes propriétés optiques et renforce donc l'hypothèse que EL2 et $\mathrm{As}_{\mathrm{Ga}}$ ont la même origine.
\end{abstract}

\begin{abstract}
The photo response of the EL2 absorption band and of the As $\mathrm{Ga}_{\mathrm{Ga}}^{+} \mathrm{ESR}$ signal in GaAs is described and compared with the basic optical properties of the EL2 mid-gap level, as inferred from photocapacitance spectroscopy. Changes in the EL2 absorption band intensity induced by secondary below band-gap light are analysed and are explained in terms of the EL2 optical cross-sections known from photocapacitance studies. The thermal recovery of the EL2 absorption band following complete quenching-is discussed. Below band-gap light can also induce changes in the GaAs absorption spectrum below $0.75 \mathrm{eV}$. They are attributed to optically induced persistent free carriers. Their generation is related to the presence of EL2. The photoresponse of the $\mathrm{As}_{\mathrm{Ga}}^{+}$ESR signal in GaAs is reviewed. These results reveal that EL2 and $\mathrm{As}_{\mathrm{Ga}}$ have practically the same optical properties and provide the best evidence that EL2 and the $\mathrm{As}_{\mathrm{Ga}}^{+} \mathrm{ESR}$ are induced by the same defect.
\end{abstract}

\section{Introduction.}

The deep defect in GaAs nowadays called EL2 manifested itself by a broad below-gap absorption band already in 1962 [1]. However the ubiquitous nature of EL2 and its great importance for the electronic properties of bulk and vapor phase epitaxial GaAs were recognized considerably later, in the second half of the seventies. During that period EL2 was assessed mainly with space charge capacitance techniques. These studies revealed that EL2 is an intrinsic mid-gap donor not related to impurities and especially not to oxygen. On the other hand these studies did not provide information about the chemical nature of EL2 and its microscopic structure.

In 1980 the arsenic antisite defect, $\mathrm{As}_{\mathrm{Ga}}$, was discovered by electron-spin-resonance (ESR) [2]. Speculations that the $\mathrm{As}_{\mathrm{Ga}}$ defect might be respon- sible for the EL2 level arose early [3-5] already at a time where nothing but the bare $\mathrm{As}_{\mathrm{Ga}}^{+}$ESR spectrum was known. Subsequent ESR investigations showed that $\mathrm{As}_{\mathrm{Ga}}$ is in fact an omnipresent defect in semiinsulating bulk GaAs [6-9] with typical $\mathrm{As}_{\mathrm{Ga}}^{+}$concentrations in the lower $10^{16} \mathrm{~cm}^{-3}$ range. Also the high temperature annealing behaviour of $\mathrm{As}_{\mathrm{Ga}}$ turned out to be compatible with that of EL2 [7, 10]. However, the most direct and convincing correlation between EL2 and $\mathrm{As}_{\mathrm{Ga}}$ was established by the comparison of the optical properties of the two defects. Photo ESR data $[8,11-15]$ indicated that $\mathrm{As}_{\mathrm{Ga}}$ is a deep double donor with its first level at mid-gap. They also demonstrated that the spectral dependencies of the $\mathrm{As}_{\mathrm{Ga}}$ mid-gap level ionization cross-sections are very similar to those of EL2 and that $\mathrm{As}_{\mathrm{Ga}}^{+}$shows a persistent quenching behaviour which is analogous to that of EL2. These striking similarities are the 
most reliable evidence that the EL2 level and the $\mathrm{As}_{\mathrm{Ga}}^{+}$ESR spectrum involve one and the same defect, even if the exact microscopic structure of EL2 is still a matter of debate, see other reviews in this volume.

In the following we will first recall the optical properties of the EL2 level which were originally inferred from photocapacitance measurements [16, 17]. We then present the optical response of the EL2 absorption band and show that it can be fully understood in terms of the photocapacitance results. Chapter 4 reviews ESR results for $\mathrm{As}_{\mathrm{Ga}}$ with special emphasis on the optical response of this defect in asgrown undoped semi-insulating GaAs. In chapter 5 it is pointed out that persistent free carriers can be generated during EL2 bleaching.

\section{Optical properties of EL2 from photocapacitance measurements.}

As far as ionization of a deep level defect is concerned, the optical properties of a conventional defect are completely characterized by an electron ionization cross-section $\sigma_{\mathrm{n}}^{0}(h \nu)$ and a hole ionization cross-section $\sigma_{\mathrm{p}}^{0}(h \nu)$. These quantities describe the relative probability of electron and hole excitation into the conduction and valence bands respectively as a function of photon energy. For the mid-gap level of EL2 these cross-sections have been measured with Deep Level Optical Spectroscopy (DLOS) [16]. This is a photocapacitance technique in which the space charge region of a reverse biased Schottky diode is illuminated with monochromatic light to ionize the deep level. This results in a change of the diode capacitance. If this change is recorded as a function of illumination time one obtains a photocapacitance transient. The initial slope of this transient is proportional to $\sigma_{\mathrm{n}}^{0}$ or $\sigma_{\mathrm{p}}^{0}$ depending on the initial conditions that have been set (all centres filled with electrons or all centres filled with holes). Scanning the photon energy $h \nu$ point by point up to the band edge then provides the complete spectral dependence of the cross-section. In this way $\sigma_{n}^{0}(h \nu)$ and $\sigma_{\mathrm{p}}^{0}(h \nu)$ of the EL2 mid-gap level have been determined [16]. They are schematically plotted in figure 1a. The ratio $\sigma_{\mathrm{n}}^{0} / \sigma_{\mathrm{p}}^{0}$ at $h \nu=1.17 \mathrm{eV}$ has been adopted from reference [18]. Note that the $\sigma_{n}^{0}(h \nu)$ curve corresponds to a low temperature measurement, while the $\sigma_{\mathrm{p}}^{0}(h \nu)$ curve has been measured at room temperature. This difference accounts for the fact that the $\sigma_{\mathrm{p}}^{0}(h \nu)$ threshold is somewhat below the low temperature mid-gap position, $h \nu \approx$ $0.75 \mathrm{eV}$. Recent measurements of $\sigma_{\mathrm{p}}^{0}(h \nu)$ at $80 \mathrm{~K}$ [19] confirm that its low energy threshold is near $0.75 \mathrm{eV}$.

Since the cross-sections in figure 1a are essential for comparison purposes in subsequent chapters we

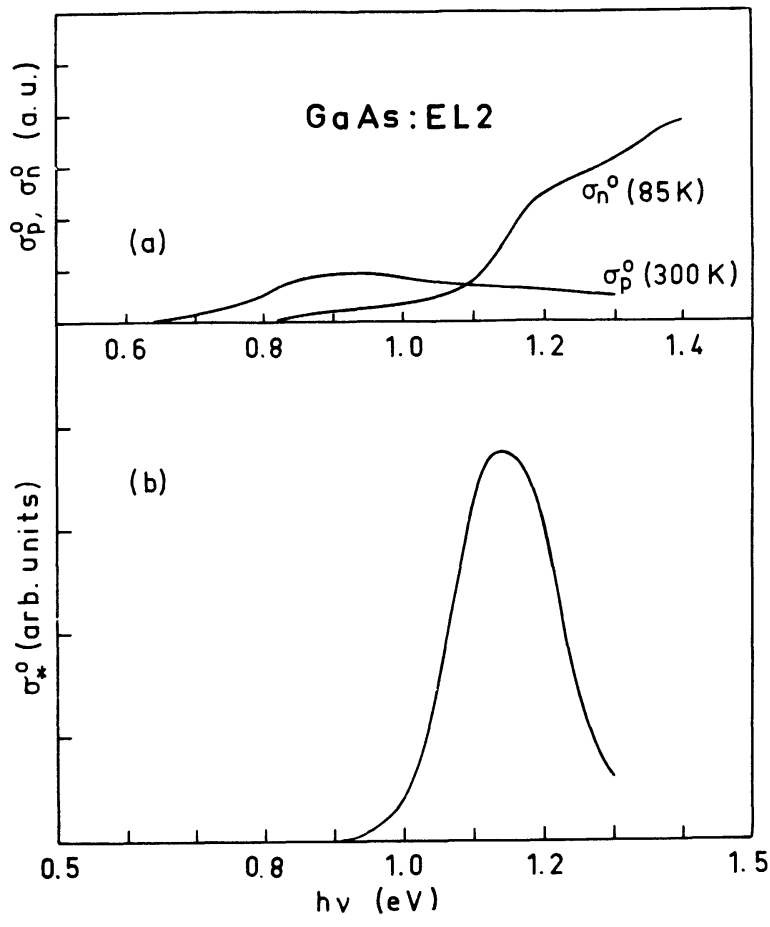

Fig. 1. - (a) Spectral dependence of photo-ionization cross-sections for the EL2 mid-gap level [16]. (b) Spectral dependence of the EL2 persistent photocapacitance quenching effect at $80 \mathrm{~K}$ [17].

want to point out some relevant features. The $\sigma_{\mathrm{n}}^{0}(h \nu)$ curve rises monotonically with increasing photon energy up to the band edge. Some structure is visible which has been attributed to electron transitions to higher conduction band minima [16]. In contrast the $\sigma_{\mathrm{p}}^{0}(h \nu)$ curve is peaked near $0.95 \mathrm{eV}$. In the lower energy region, $h \nu<1.1 \mathrm{eV}$, the value of $\sigma_{\mathrm{p}}^{0}(h \nu)$ exceeds that of $\sigma_{\mathrm{n}}^{0}(h \nu)$ while above $1.1 \mathrm{eV}$ the relation is reversed. For $h \nu \approx$ $1.1 \mathrm{eV}$ the two cross-sections are equal in magnitude. Therefore the optical absorption due to the EL2 mid-gap level at this energy is independent of the charge state.

Sofar we have considered the conventional optical properties of the EL2 mid-gap level. Its unusual and peculiar behaviour was also discovered by photocapacitance measurements $[17,20,21]$. These studies revealed that a third optical cross-section, $\sigma_{*}^{0}$, is required to fully describe the photoresponse of the mid-gap level. The unusual behaviour is apparent only at temperatures below $120 \mathrm{~K}$ and only in a narrow range of photon energies, $1.0 \mathrm{eV}<h \nu<$ $1.4 \mathrm{eV}$. It manifests in the following way. Assume that a photocapacitance experiment is performed under the above conditions and with all mid-gap levels filled with electrons before illumination. In this case the capacitance transient first increases (due to electron emission), see the $h \nu=1.15 \mathrm{eV}$ transient in figure 2 , goes through a maximum but 


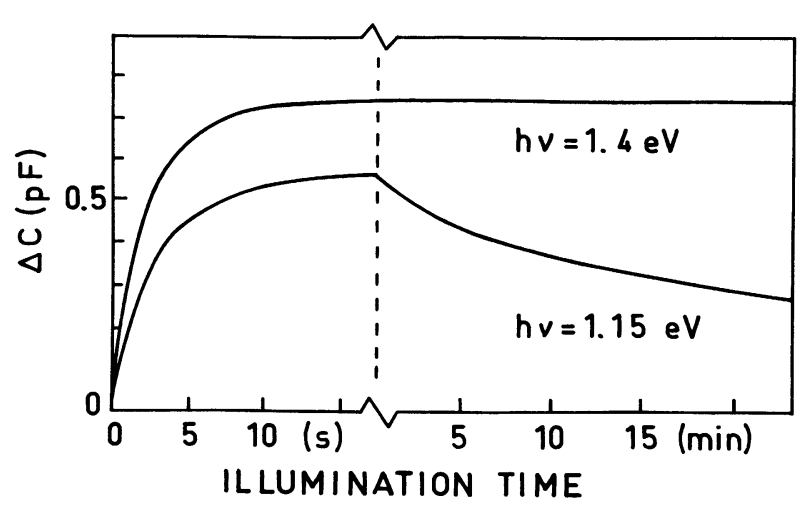

Fig. 2. - EL2 photocapacitance transients observed on $\mathrm{n}-\mathrm{GaAs}$ Schottky diodes for two photon energies $h \nu$ [21].

then decreases and reaches a final value close to that before illumination. The whole transient thus is nonmonotonic. Switching off the light and subsequently illuminating the diode no longer produces a significant change of its capacitance. Heating of the sample to temperatures above $130 \mathrm{~K}$ is required to restore its original photosensitive state. This anomalous phenomenon is called the persistent photocapacitance quenching (PPCQ) effect. In contrast, the normal photocapacitance behaviour is given by the monotonic $h \nu=1.4 \mathrm{eV}$ transient in figure 2. Physically the PPCQ effect has been attributed [17] to a structural rearrangement of the EL2 defect accompanied by the disappearance of the mid-gap level (normal state) and the generation of an optically inactive level (metastable state), see other reviews in this volume. The optical crosssection, $\sigma_{*}^{0}(h \nu)$, for this transformation, as obtained from photocapacitance studies, is shown in figure $1 \mathrm{~b}$. This is the so called persistent quenching band of EL2. Recent high-resolution photocapacitance measurements $[22,23]$ have shown that this band is preceeded by a weak zero-phonon-line at $h \nu=1.038 \mathrm{eV}$.

In most space charge capacitance experiments the

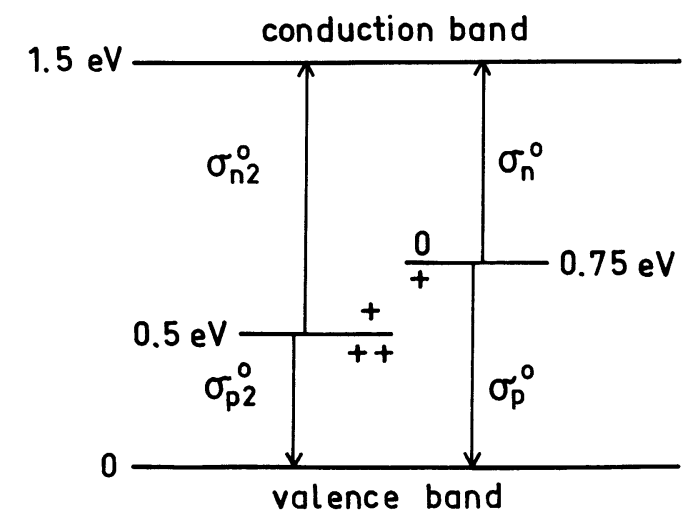

Fig. 3. - The two donor levels of EL2 at low temperature as inferred from photocapacitance studies. Observed electron-(hole) transitions are marked by arrows. Note that the same level scheme is valid for the $\mathrm{As}_{\mathrm{Ga}}$ double donor.
EL2 defect was reported to behave as a single donor. There is however growing evidence that a second donor level is associated with EL2. Both photocapacitance $[19,24,25,27]$ and deep level transient spectroscopy $[26,27]$ strongly indicate that this second level is located about $1.0 \mathrm{eV}$ below the conduction band edge. Thus from space charge capacitance studies EL2 appears to be a double donor with levels at $E_{\mathrm{c}}-0.75 \mathrm{eV}$ and at $E_{\mathrm{c}}-$ $1.0 \mathrm{eV}$ as sketched in figure 3 . The spectral dependence for photoionization of the second hole is shown in figure 4.

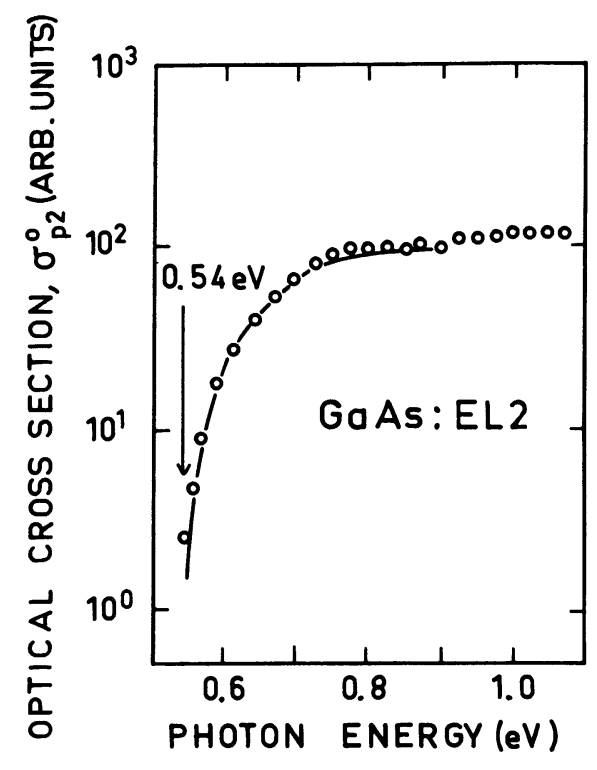

Fig. 4. - Photoionization cross-section for the second hole of EL2 at $77 \mathrm{~K}$. Full line represents a theoretical fit to the data points [25].

\section{Optical response of the EL2 absorption and ther- mal regeneration from the metastable state.}

In this chapter we concentrate on the changes in the EL2 absorption spectrum, which can be induced by monochromatic secondary light. The steady state optical properties of EL2 are treated in other articles within this volume.

As outlined in chapter 2 the following optically induced transitions can occur : (i) an electron can be transferred from the EL2 mid-gap level in its neutral charge state $\left(\mathrm{D}^{0}\right)$ to the conduction band, according to the optical electron ionization cross-section $\sigma_{\mathrm{n}}^{0}(h \nu)$; (ii) a hole can be transferred from the ionized charge state $\left(\mathrm{D}^{+}\right)$to the valence band according to the optical hole ionization cross-section $\sigma_{\mathrm{p}}^{0}(h \nu)$; (iii) an « internal » (non-ionizing) transition can occur from the neutral charge state $\left(\mathrm{D}^{0}\right)$ according to the optical « quenching » crosssection $\sigma_{*}^{0}(h \nu)$. Transitions involving the doubly ionized charge state are not observed under normal conditions and can be neglected here. Thus the 
optical absorption spectrum is a superposition of three subspectra.

$\alpha(h \nu)=N\left[f_{0}\left(\sigma_{\mathrm{n}}^{0}(h \nu)+\sigma_{*}^{0}(h \nu)\right)+f_{+} \sigma_{\mathrm{p}}^{0}(h \nu)\right]$.

Here $N$ is the total concentration of EL2 centres in the normal state, while $f_{0}, f_{+}$describe the fractional occupation of the neutral $\left(\mathrm{D}^{0}\right)$ and singly ionized $\left(\mathrm{D}^{+}\right)$charge state, where $f_{0}+f_{+}=1$.

The EL2 absorption spectrum in figure 5 is typical for undoped semi-insulating GaAs [28, 29]. It has been pointed out [28] that the remarkable similarity between $\alpha(h \nu)$ and $\sigma_{\mathrm{n}}^{0}(h \nu)$ indicates predominance of the neutral EL2 charge state $\left(f_{0}>f_{+}\right)$. The contribution from $\sigma_{*}^{0}(h \nu)$ is expected to be small, as suggested by the lower cross-section compared to $\sigma_{\mathrm{n}}^{0}(h \nu)$ and $\sigma_{\mathrm{p}}^{0}(h \nu)$ [16]. However, the sharp zero phonon line, first reported in 1983 [30] and shown in the insert of figure 5 , is interpreted as absorption due to $\sigma_{*}^{0}(h \nu)[22,23]$, see chapter 2 .

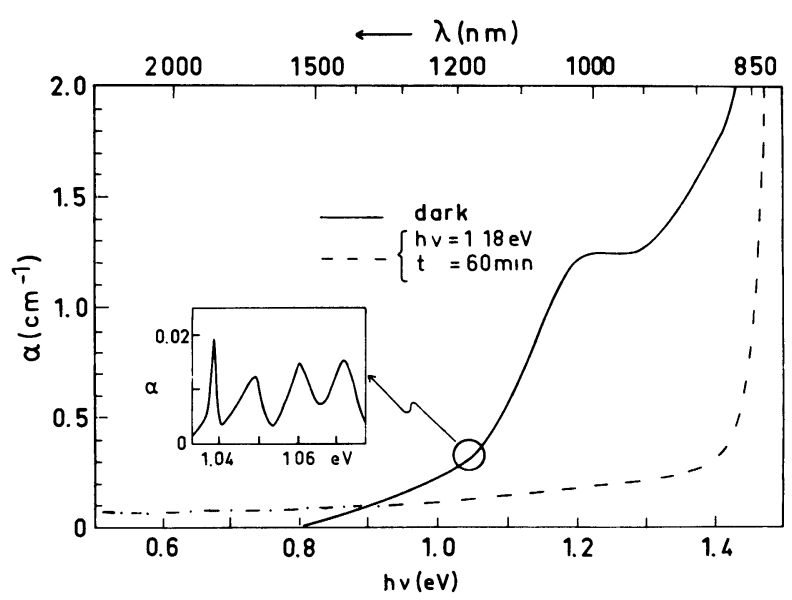

Fig. 5. - Optical absorption from EL2 centres in GaAs after cooling to $10 \mathrm{~K}$ in the dark (full curve) and after bleaching for $60 \mathrm{~min}$ with secondary light of $1.18 \mathrm{eV}$ (dash-dot curve). The insert shows an enlarged view of the zero phonon line with three side-bands [29].

The typical photoresponse experiment is performed at low temperature $(10 \mathrm{~K})$ in a set-up, where the absorption is monitored with a double beam grating spectrometer while the sample is illuminated with monochromatic secondary light at a power level of $2 \mathrm{~mW} / \mathrm{cm}^{2}$ for a spectral slit width of $40 \mathrm{~nm}$. The absorption transients shown in figure 6 are characteristic for the EL2 donor : a fast increase is followed by a slow decrease, as previously observed in photocapacitance [17] and photo-ESR experiments [13]. For the interpretation we start from equation (1). In the short-time regime (a few seconds) we can set $N=$ const. and for the change in

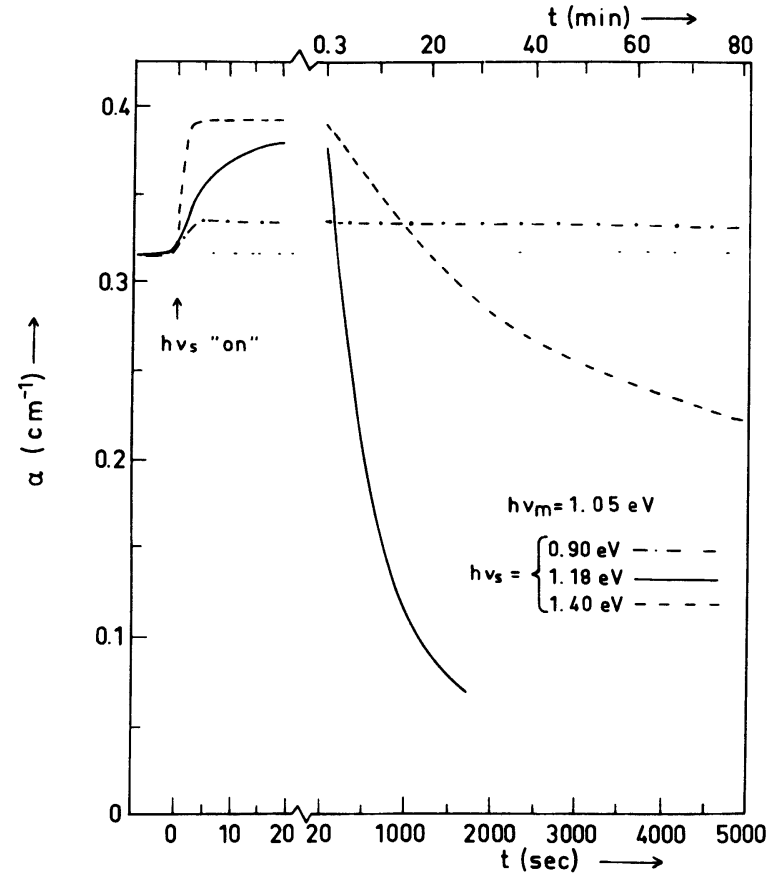

Fig. 6. - Absorption transients for three different energies of secondary light. Plotted is the absorption at $1.05 \mathrm{eV}$, corrected for the extra absorption by persistent electrons [29].

fractional occupation the sum rule requires $\Delta f_{0}=$ $-\Delta f_{+}$thus

$$
\Delta \alpha(h \nu)=N\left[\Delta f_{+}\left(\sigma_{\mathrm{p}}^{0}(h \nu)-\sigma_{\mathrm{n}}^{0}(h \nu)\right)\right] .
$$

In figure 6 the absorption was monitored at $1.05 \mathrm{eV}$, where $\left(\sigma_{\mathrm{p}}^{0}-\sigma_{\mathrm{n}}^{0}\right)>0$. The three transients in figure 6 show that $\Delta \alpha$ is positive in the rising part. This implies $\Delta f_{+}>0$, according to equation (2). Confirmation comes from the difference spectrum, taken after $6 \mathrm{~s}$ of $1.24 \mathrm{eV}$ illumination, see figure 7a. As predicted by equation (2) the spectral shape follows the $\sigma_{\mathrm{p}}^{0}-\sigma_{\mathrm{n}}^{0}$ curve, shown in figure $7 \mathrm{~b}$. Also indicated is the flat infrared absorption by persistent photo-generated electrons (see chapter 5). From the exponential transients in the short time regime the spectrally resolved rate constants have been determined $[29,31]$. They are shown for $\Delta f_{+}>0$ (starting from the dark spectrum) in figure $8 \mathrm{a}$ and for $\Delta f_{+}<0$ (starting from a high $f_{+}$state, prepared by illumination with $1.40 \mathrm{eV}$ light) in figure $8 \mathrm{~b}$. The solution of the rate equation predicts [16] that the spectral shape is determined by the sum $\sigma_{\mathrm{n}}^{0}+$ $\sigma_{\mathrm{p}}^{o}$, see figure $8 \mathrm{c}$. Indeed the curves in figure $8 \mathrm{a}$ and $8 \mathrm{~b}$ are similar to the curve in figure $8 \mathrm{c}$.

The photo induced changes of the EL2 absorption spectrum described by $\sigma_{\mathrm{n}}^{0}$ and $\sigma_{\mathrm{p}}^{0}$ are optically reversible. Switching the energy of the secondary light between 1.4 and $0.9 \mathrm{eV}$ causes the EL2 centre to switch between the ionized (large $f_{+}$) and neutral 


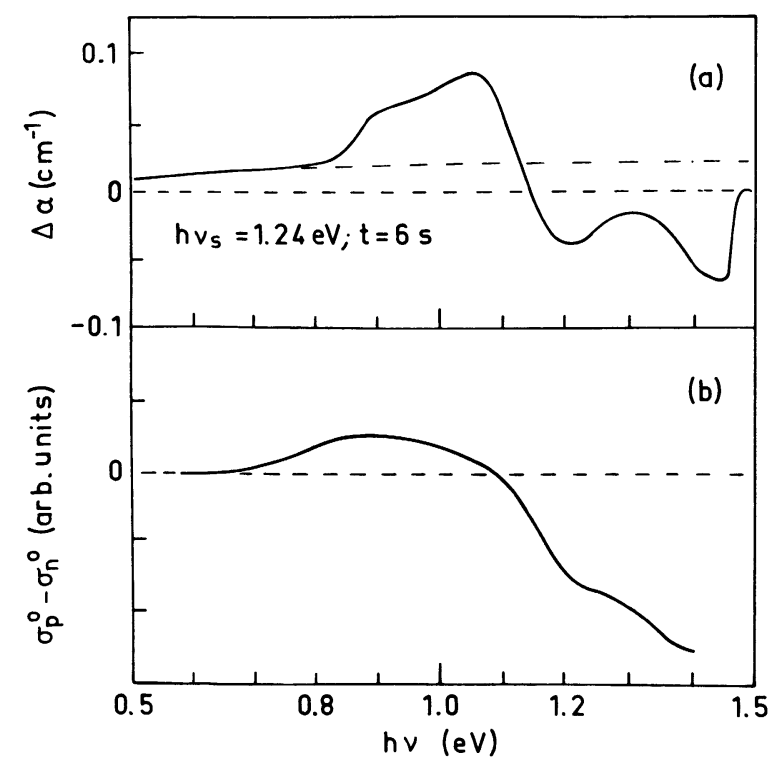

Fig. 7. - (a) Difference spectrum, observed after $6 \mathrm{~s}$ of illumination with $1.24 \mathrm{eV}$ light by subtracting the dark spectrum [29]. The dash-dot line indicates the spectrally flat absorption by persistent electrons. In (b) the difference $\left(\sigma_{\mathrm{p}}^{0}-\sigma_{\mathrm{n}}^{0}\right)$ of the optical ionization cross-sections is shown, as obtained from figure 1a.

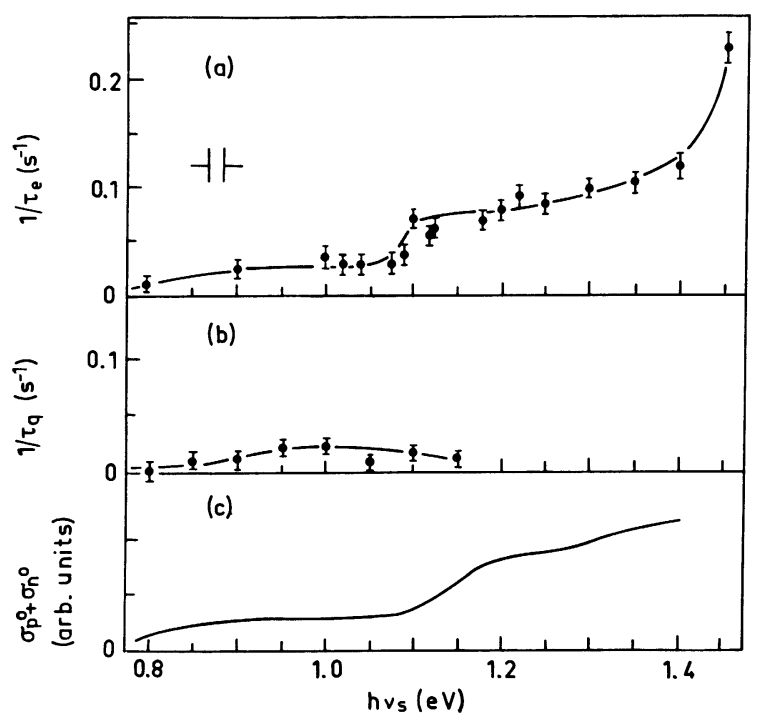

Fig. 8. - Spectrally resolved rate constants [31] for the optically reversable enhancement (a) and quenching (b) of the $\mathrm{D}^{+}$charge state of EL2. For (a) the initial state is the dark condition. For (b) a high $\mathrm{D}^{+}$concentration was prepared by preillumination with $1.4 \mathrm{eV}$ light. In (c) the sum $\left(\sigma_{\mathrm{p}}^{0}+\sigma_{\mathrm{n}}^{0}\right)$ of the optical ionization cross-sections is shown, as obtained from figure 1a.

(small $f_{+}$) charge state. No fatigue was observed even after 10 cycles.

A quite different photoresponse is observed in the long-time regime $(10 \mathrm{~min})$. The rate constants are 100 times lower (note the scale change in Fig. 6) and the process can not be reversed by optical irradiation in the energy range $0.5-1.5 \mathrm{eV}$. As mentioned in chapter 2, this persistent photo-quenching involves a transformation of the normal EL2 centre into a metastable state. The metastable EL2 centre has no optical absorption, thus the normal EL2 absorption can be completely bleached, as reported in 1981 [28] and shown in figure 5. In the long-time regime $f_{0}$ and $f_{+}$are independent of time, and the square bracket in equation (1) can be replaced by a constant value. Thus the decrease in absorption at a monitor energy of $1.05 \mathrm{eV}$ (see Fig. 6) is given by

$$
\Delta \alpha_{1.05}(t)=\Delta N(t) \sigma_{1.05}^{0} \text {. }
$$

Here $\Delta N(t)$ is the change in the concentration of normal EL2 centres, i.e. $\Delta N(t)<0$ for quenching. The corresponding transients are exponentials and the spectrally resolved rate constants have been determined point by point [29, 31]. Later, continuous curves were obtained [32] and these are shown in figure 9. The spectral shape is the same as that found in photocapacitance quenching [17] (see Fig. 1b). Also shown in figure 9 is the temperature depen-

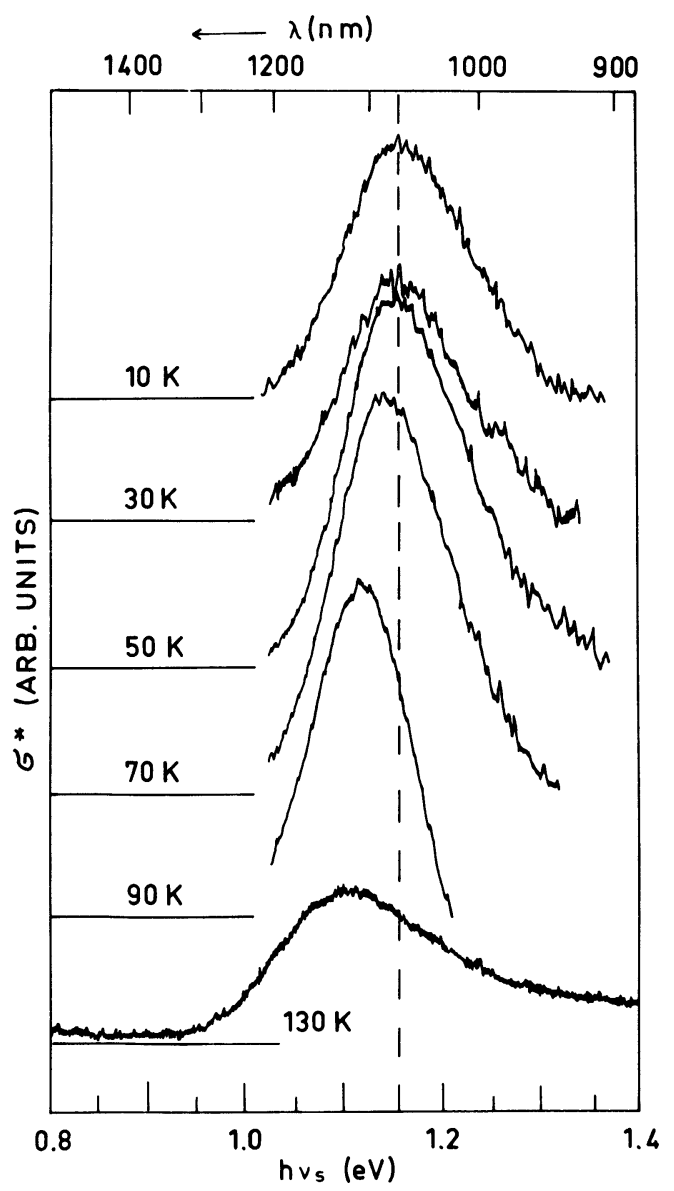

Fig. 9. - Spectrally resolved cross-section for the persistent quenching of the EL2 absorption. The continuous curves for 10 to $90 \mathrm{~K}$ and the curve for $130 \mathrm{~K}$ were obtained using techniques, described in [32]. The high energy wing $(h \nu>1.15 \mathrm{eV})$ of the $90 \mathrm{~K}$ curve is depressed by photon assisted regeneration [32]. 
dence; the peak shifts to lower energies with increasing temperature similar to observations in photocapacitance [33]. The zero-phonon-line at $1.038 \mathrm{eV}$ with its phonon side bands (see Fig. 5) is part of the quenching spectrum and can be observed under conditions of high resolution and good signal to noise ratio [34].

At temperatures above $110 \mathrm{~K}$ the metastable EL2 centres return to the normal state by a thermally activated process. The corresponding Arrhenius diagram is shown in figure 10. The data from optical

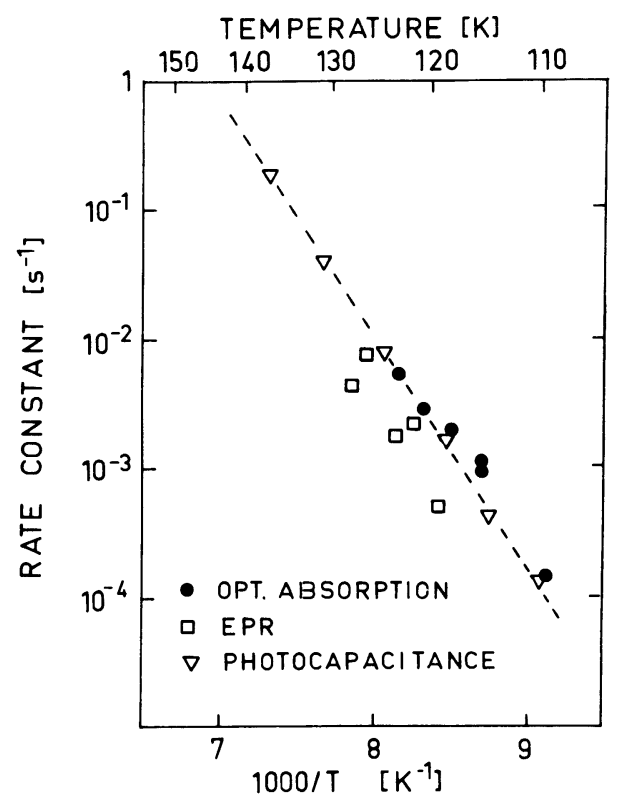

Fig. 10. - Arrhenius plot for the thermal regeneration of EL2 from the metastable state. Comparison of data from optical absorption [31], ESR of the $\mathrm{As}_{\mathrm{Ga}}^{+}$[35] and photocapacitance [33]. The broken line corresponds to equation (4).

absorption [31] are compared with results from photocapacitance [33] and photo-ESR [35]. Despite the slight offset of the ESR data the agreement is remarkable and yields a thermal regeneration rate $r$ given by

$$
r=r_{0} \exp (-0.36 \mathrm{eV} / k T) ; r_{0}=3.6 \times 10^{12} \mathrm{~s}^{-1} .
$$

Later it was shown, that one temperature scan is sufficient to obtain an Arrhenius type diagram from which the activation energy $\Delta E$ and the pre-exponential $r_{0}$ can be determined [32]. An example is shown in figure 11. Sample No. 1 was undoped semiinsulating GaAs, yielding $\Delta E=0.38 \mathrm{eV}$. Sample No. 2 was $n$-doped $\left(1.5 \times 10^{17} \mathrm{Te}\right)$ and yielded the much lower value $\Delta E=0.063 \mathrm{eV}$. The reduction in activation energy by free electrons is known since 1979 [36] from photocapacitance, using electron injection pulses $[17,33,36]$. In bulk GaAs, a
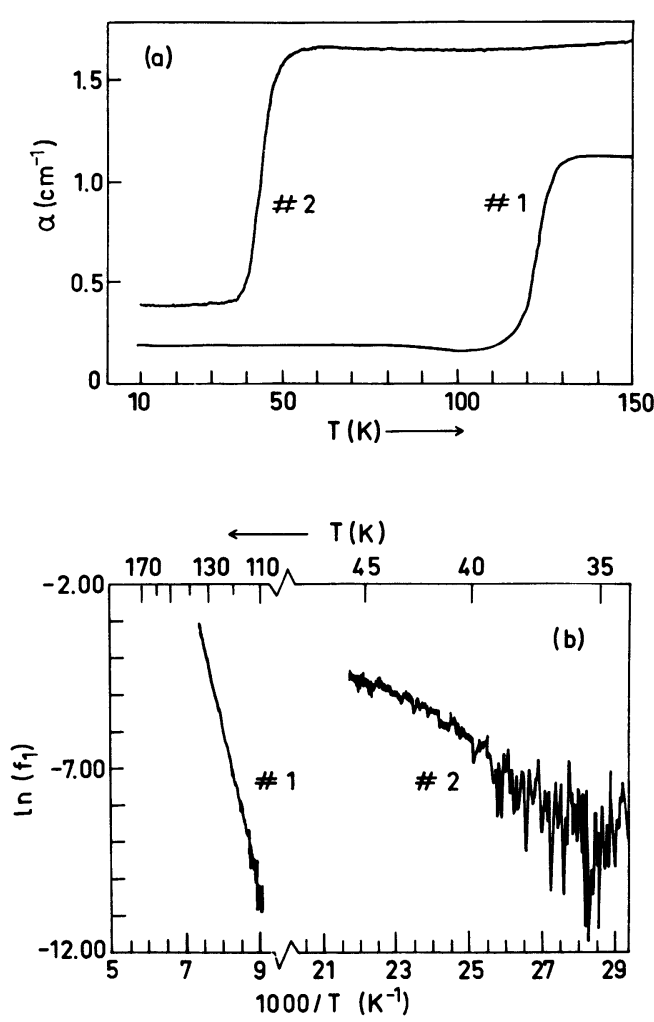

Fig. 11. - (a) Thermal recovery of the EL2 absorption in semi-insulating (\#1) and n-type (\#2) GaAs after complete bleaching. The temperature was increased at a rate of $1.7 \mathrm{~K} / \mathrm{min}$ and the absorption was monitored at $1.25 \mathrm{eV}$, which is a temperature insensitive point in the spectrum. In (b) lines of the Arrhenius type are shown, which were obtained from the data in (a). Details are given in [32].

lowering of the activation energy by n-doping has been observed only recently in EL2 absorption regeneration experiments $[32,37]$.

\section{Optical properties of the $\operatorname{As}_{\mathrm{Ga}}^{+}$ESR spectrum.}

The isolated $\mathrm{As}_{\mathrm{Ga}}$ antisite in GaAs is formally a double donor which is paramagnetic only in its singly ionized state $\mathrm{As}_{\mathrm{Ga}}^{+}$. An ESR signal which has been identified with this defect has been discovered in Bridgman-grown GaAs: $\mathrm{Cr}$ using a far infrared ( $300 \mathrm{GHz})$ ESR setup [2]. A spectrum with the same ESR parameters is observed at $9 \mathrm{GHz}$ in asgrown undoped LEC GaAs, see the example shown in figure 12. Before describing its photoresponse we want to make a few general comments.

The spectrum is characterized by its $g$-factor, $g=2.05$, and the central hyperfine coupling constant, $A=890 \times 10^{-4} \mathrm{~cm}^{-1}$. The hyperfine coupling is responsible for the four line pattern. It arises from the Fermi contact interaction of the unpaired electron's spin $S=1 / 2$ with the central ${ }^{75}$ As nucleus (spin $I=3 / 2$ ) and is proportional to the electron's density at this nucleus. Therefore the hyperfine 


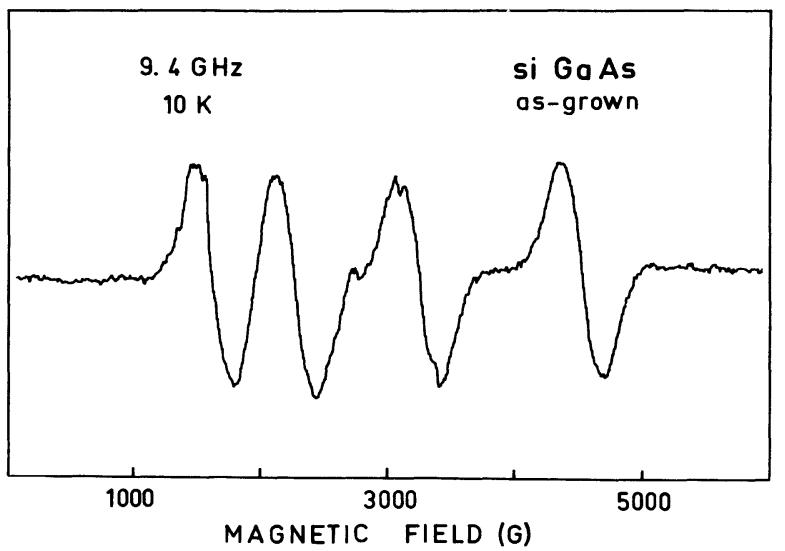

Fig. 12. - The ESR spectrum of the $\mathrm{As}_{\mathrm{Ga}}^{+}$antisite in undoped as-grown $\mathrm{GaAs}$ corresponding to an $\mathrm{As}_{\mathrm{Ga}}^{+}$concentration of about $2 \times 10^{16} \mathrm{~cm}^{-3}$. In situ illumination has been used to enhance the signal by a factor of two. Cavity background signals have been electronically substracted.

splitting is sensitive to the presence of possible other defects in the near neighbourhood of $\mathrm{As}_{\mathrm{Ga}}$. The largest hyperfine splitting is expected for isolated $\mathrm{As}_{\mathrm{Ga}}$ since a neighbouring defect will remove electron density from the $\mathrm{As}_{\mathrm{Ga}}$ nucleus especially if such a defect were charged. This is experimentally confirmed for two $\mathrm{P}_{\mathrm{Ga}}$ complexes in GaP [4] and for an $\mathrm{As}_{\mathrm{Ga}}$ complex in GaAs [38]. In these cases the reduction of the hyperfine splitting is substantial, about $30 \%$ as compared with isolated $\mathrm{P}_{\mathrm{Ga}}$ and the $\mathrm{As}_{\mathrm{Ga}}$ spectrum in figure 12. One is therefore tempted to attribute the $\mathrm{As}_{\mathrm{Ga}}$ signal in figure 12 to isolated $\mathrm{As}_{\mathrm{Ga}}$ but the information contained in the spectrum is insufficient to confirm this definitely.

Many authors have contended [35, 39-45] that several different $\mathrm{As}_{\mathrm{Ga}}$ related defects simultaneously contribute to the $\mathrm{As}_{\mathrm{Ga}}^{+}$signal in figure 12. This may be true for particle-irradiated or plastically deformed material [35] where high defect densities occur but remains speculative for as-grown material. The highfield line in figure 12 neither overlaps with other $\mathrm{As}_{\mathrm{Ga}}^{+}$lines nor with cavity background signals and thus reveals its true width $(330 \mathrm{G})$ and shape. The latter is perfectly symmetric when the magnetic field is along the main symmetry directions. It is unlikely that this would be the case if several antisite defects with different hyperfine constants and concentrations contributed to this line. For instance, a ten percent reduction in hyperfine coupling would lower the position of the uppermost line by about $150 \mathrm{G}$ which is almost one half of its linewidth. We therefore keep the view that in as-grown undoped GaAs the $\mathrm{As}_{\mathrm{Ga}}^{+}$ESR spectrum arises from a single well defined $\mathrm{As}_{\mathrm{Ga}}$ antisite, irrespective of the question whether this is isolated $\mathrm{As}_{\mathrm{Ga}}$ or an $\mathrm{As}_{\mathrm{Ga}}$ complex as suggested by some authors [46, 47].

In a photo-ESR experiment the sample under investigation is illuminated with (monochromatic) light within the microwave cavity and the effect of light on the ESR signal intensity is studied. Such experiments are usually performed on bulk material. Thus carrier recombination competes with photoionization and the rate equations governing the kinetics of these processes are generally complicated [48]. In most cases it is therefore difficult to obtain the ionization cross-sections of a defect level associated with an ESR signal especially if the two cross-sections overlap on the energy scale. However, it is comparatively easy to measure photo-ionization thresholds to determine the energy level position [49].

Such threshold measurements were performed for $\mathrm{As}_{\mathrm{Ga}}^{+}$in plastically deformed semi-insulating and $\mathrm{p}$ type material $[11,12,50]$. The use of plastically deformed crystals was motivated by the higher $\mathrm{As}_{\mathrm{Ga}}^{+}$concentration as compared to as-grown material. The result of these photo-ESR measurements are shown in figure 13. For the semi-insulating material two quenching thresholds near $0.75 \mathrm{eV}$ and $1.0 \mathrm{eV}$ are observed which were interpreted as transitions converting the paramagnetic $\mathrm{As}_{\mathrm{Ga}}^{+}$state into the diamagnetic $\mathrm{As}_{\mathrm{Ga}}^{0}$ and $\mathrm{As}_{\mathrm{Ga}}^{2+}$ states respectively. In addition in the p-type material an enhancement step near $0.5 \mathrm{eV}$ is observed which was attributed to a transition converting $\mathrm{As}_{\mathrm{Ga}}^{2+}$ into $\mathrm{As}_{\mathrm{Ga}}^{+}$. On the basis of these results the $\mathrm{As}_{\mathrm{Ga}}$ double donor model sketched in the insert of figure 13 has been suggested [11]. Note that this model for $\mathrm{As}_{\mathrm{Ga}}$ is identical with the level scheme of EL2 recently

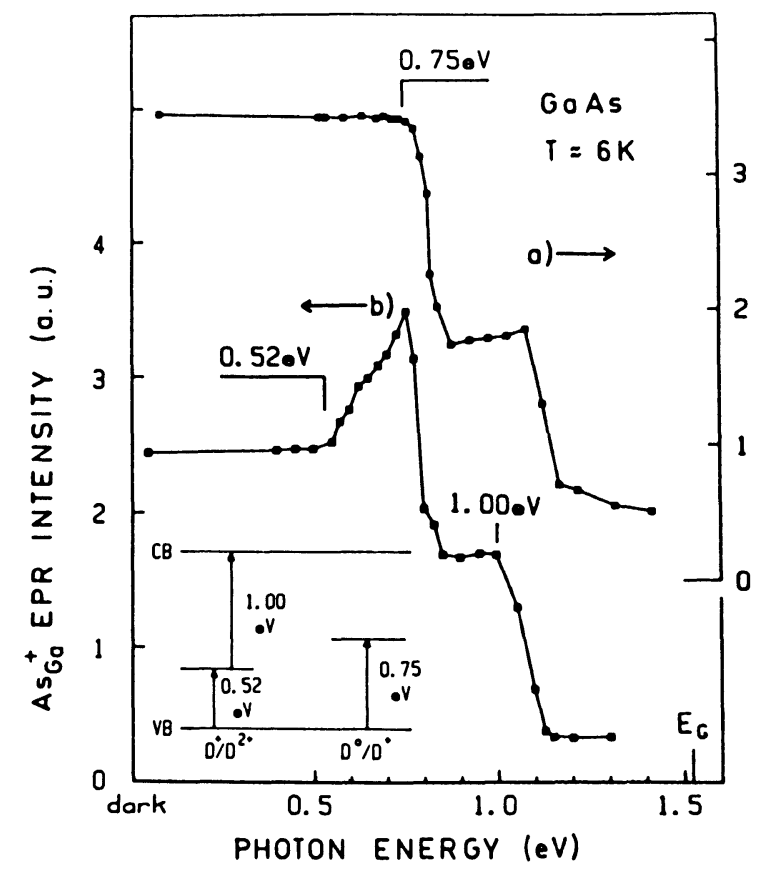

Fig. 13. - Photoresponse of the $\mathrm{As}_{\mathrm{Ga}}^{+}$ESR in plastically deformed GaAs [11]. (a) Semi-insulating material, (b) ptype material. The $\mathrm{As}_{\mathrm{Ga}}$ double donor level scheme inferred from these data is shown in the insert. 
inferred from capacitance techniques, see chapter 2. The mid-gap location of the first $\mathrm{As}_{\mathrm{Ga}}$ donor level provided the first direct microscopic link between $\mathrm{As}_{\mathrm{Ga}}$ and EL2. Additional support for this correlation was obtained from the $\mathrm{As}_{\mathrm{Ga}}^{+}$quenching behaviour at $h \nu=1.15 \mathrm{eV}$ [12]. For this photon energy a persistent (i.e. optically irreversible) quenching of the $\mathrm{As}_{\mathrm{Ga}}^{+}$signal is observed and heating up of the sample is required to restore the original signal intensity. Such a behaviour is reminiscent of the EL2 persistent photocapacitance quenching effect, see chapter 2.

We now focus attention on the properties of the $\mathrm{As}_{\mathrm{Ga}}^{+}$spectrum in as-grown GaAs. In the dark the equilibrium concentration of $\mathrm{As}_{\mathrm{Ga}}^{+}$depends critically on the Fermi level position [14]. The strongest $\mathrm{As}_{\mathrm{Ga}}^{+}$signals are present in deliberately acceptor doped $(\mathrm{C}, \mathrm{Zn}, \mathrm{Cr}, \mathrm{Fe})$ high-resistivity samples and optical enhancement is not possible since all $\mathrm{As}_{\mathrm{Ga}}$ centres are compensated i.e. in the $\mathrm{As}_{\mathrm{Ga}}^{+}$state. In undoped semi-insulating material the dark signal can be either enhanced or reduced depending on the photon energy chosen. Finally, in undoped lightly ntype material the $\mathrm{As}_{\mathrm{Ga}}^{+}$dark signal is very weak, practically all centres are in the $\mathrm{As}_{\mathrm{Ga}}^{0}$ state, but can be strongly enhanced with light. These results demonstrate that a shift of the Fermi level from below to above mid-gap is accompanied by the conversion of $\mathrm{As}_{\mathrm{Ga}}^{+}$into $\mathrm{As}_{\mathrm{Ga}}^{0}$ and thus provide independent support for the near mid-gap position of the $\mathrm{As}_{\mathrm{Ga}}^{0} / \mathrm{As}_{\mathrm{Ga}}^{+}$level. This is an essential point since it assures that the $0.75 \mathrm{eV}$ quenching threshold in figure 13 is related to a direct photoionization of $\mathrm{As}_{\mathrm{Ga}}$.

The photo-ESR data in figure 13 are unsatisfactory in two respects. First, they do not provide spectral information about the optical cross-sections of the $\mathrm{As}_{\mathrm{Ga}}^{0} / \mathrm{As}_{\mathrm{Ga}}^{+}$mid-gap level. Second the use of plastically deformed material might have been a disadvantage. Plastic deformation not only generates $\mathrm{As}_{\mathrm{Ga}}$ antisites but also deep acceptor centres [51] and their photoresponse could have interferred with that of $\mathrm{As}_{\mathrm{Ga}}$. To avoid this potential complication photoESR measurements were performed on as-grown semi-insulating GaAs and it has been attempted to measure approximate cross-sections for the $\mathrm{As}_{\mathrm{Ga}}$ mid-gap level $[13,14]$. Results for the $\mathrm{As}_{\mathrm{Ga}}^{+}$enhancement and quenching efficiency are shown in figure 14. The enhancement curve (process $\mathrm{As}_{\mathrm{Ga}}^{0}+$ $\left.h \nu \rightarrow \mathrm{As}_{\mathrm{Ga}}^{+}+\mathrm{e}^{-}\right)$rises almost monotonically up to the band edge and resembles the EL2 electron ionization cross-section $\sigma_{\mathrm{n}}^{0}(h \nu)$, compare chapter 2 . On the other hand the quenching curve exhibits two bands peaked near $0.9 \mathrm{eV}$ and $1.2 \mathrm{eV}$. The nature of the quenching within the two bands is quite different. For the $0.9 \mathrm{eV}$ band it is optically reversible (process $\mathrm{As}_{\mathrm{Ga}}^{+}+h \nu \rightarrow \mathrm{As}_{\mathrm{Ga}}^{0}+$ hole) indicative of hole ex-
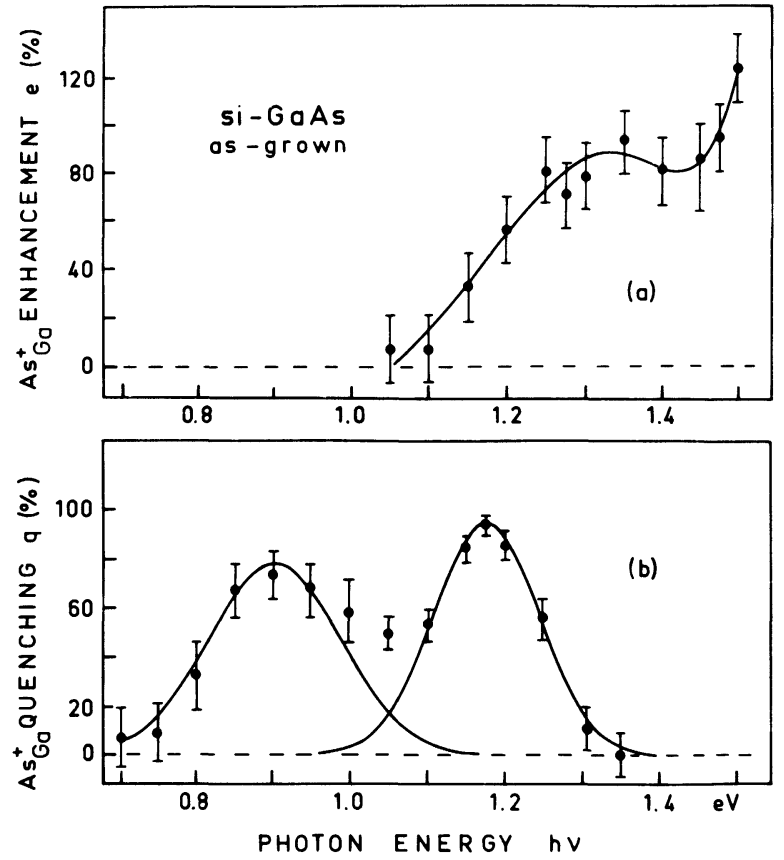

Fig. 14. - (a) Spectral dependence of $\mathrm{As}_{\mathrm{Ga}}^{+}$enhancement efficiency in as-grown GaAs. (b) Spectral dependence of $\mathrm{As}_{\mathrm{Ga}}^{+}$quenching efficiency [13].

change between $\mathrm{As}_{\mathrm{Ga}}$ and other deep centres $[9,52$, 53]. Note that the shape of this band up to $1.05 \mathrm{eV}$ looks very similar to the $\sigma_{\mathrm{p}}^{0}(h \nu)$ cross-section of EL2. For the $1.2 \mathrm{eV}$ band the quenching is persistent i.e. the $\mathrm{As}_{\mathrm{Ga}}^{+}$spectrum cannot be restored with light in the range $0.5 \mathrm{eV}$ to $1.5 \mathrm{eV}$. This persistent quenching band of $\mathrm{As}_{\mathrm{Ga}}^{+}$coincides with the EL2 persistent photocapacitance quenching band. The data in figure 14 have been confirmed on as-grown undoped samples of varying stoichiometry $[8,15]$.

The most characteristic property of EL2 is the occurrence of nonmonotonic photocapacitance transients, compare figure 2 . A completely analogous effect has been established for $\mathrm{As}_{\mathrm{Ga}}[13,14]$, see figure 15. For photon energies between $1.0 \mathrm{eV}$ and $1.4 \mathrm{eV}$ the $\mathrm{As}_{\mathrm{Ga}}^{+} \mathrm{ESR}$ transients initially increase due to photoionization of $\mathrm{As}_{\mathrm{Ga}}^{0}$ but then decrease for prolonged illumination. Such nonmonotonic ESR transients are just as unusual as nonmonotonic photocapacitance transients. Below $h \nu \approx 1.0 \mathrm{eV}$ the usual monotonic ESR transients are observed.

As mentioned in chapters 2 and 3 the persistent EL2 quenching band is preceeded by a weak zerophonon-line which is related to the neutral state $\mathrm{EL}^{0}$. The $\mathrm{As}_{\mathrm{Ga}}$ ESR on the other hand is related to the singly ionized donor $\mathrm{As}_{\mathrm{Ga}}^{+}$. If EL2 and $\mathrm{As}_{\mathrm{Ga}}$ are correlated, optically induced changes of the mid-gap level occupation must be accompanied by anticorrelated intensity changes of the zero-phonon-line and the ESR signal. This is exactly what has been observed [54, 55], see figure 16. 


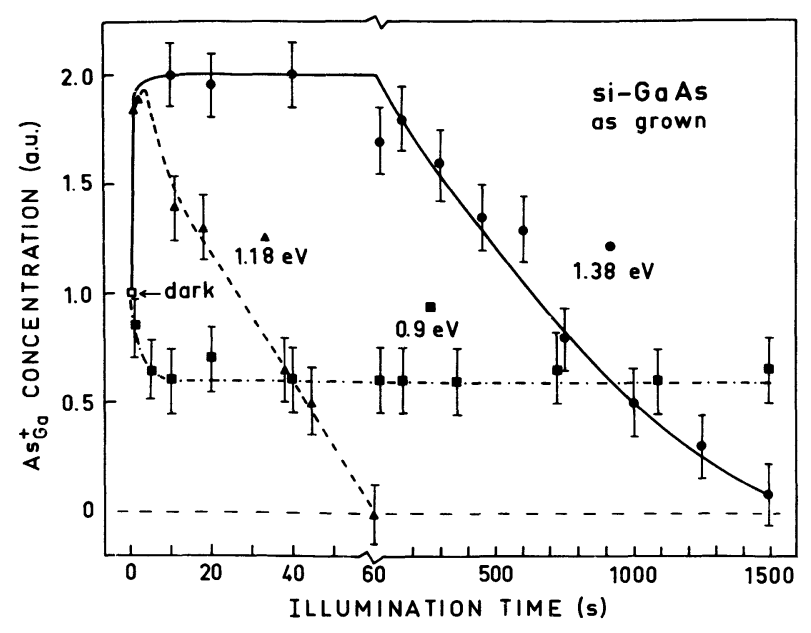

Fig. 15. $-\mathrm{As}_{\mathrm{Ga}}^{+}$ESR signal changes as a function of illumination time for three different photon energies. The $h \nu=1.18 \mathrm{eV}$ and $h \nu=1.38 \mathrm{eV}$ transients are nonmonotonic in time [13].

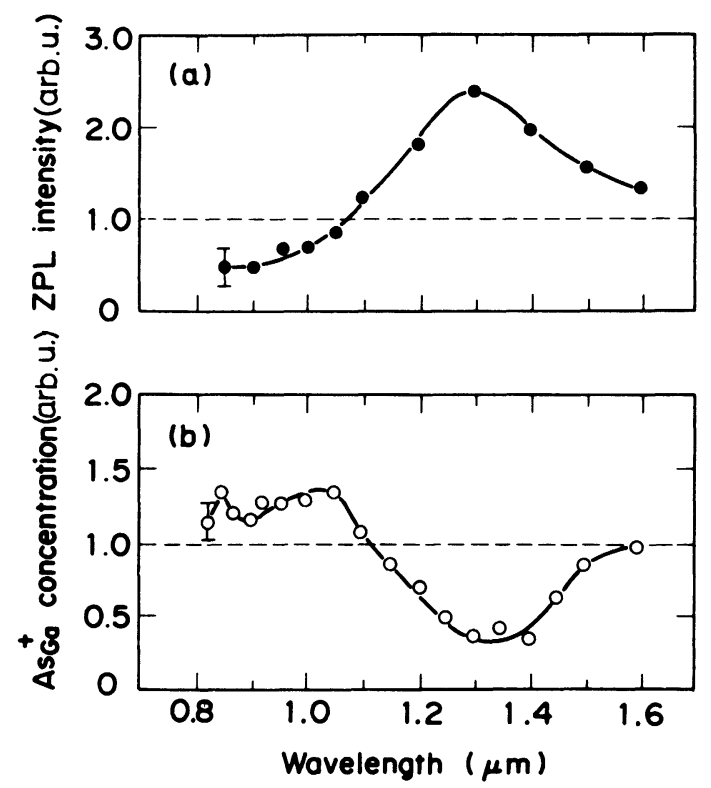

Fig. 16. - Spectral dependence of (a) the EL2 ${ }^{0} 1.038 \mathrm{eV}$ zero-phonon-line intensity and (b) the $\mathrm{As}_{\mathrm{Ga}}^{+}$ESR signal intensity. Note the anti-correlated behaviour of the two signals [54].

The photo-ESR data for as-grown GaAs presented above reveal that the optical properties of EL2 and $\mathrm{As}_{\mathrm{Ga}}$ are virtually the same. At present they provide the most direct and convincing evidence that EL2 and the $\mathrm{As}_{\mathrm{Ga}}$ ESR are induced by the same defect.

So far conventional ESR evidence for the second $\mathrm{As}_{\mathrm{Ga}}$ donor level in as-grown $\mathrm{GaAs}$ has not been reported, possibly because the photoresponse of this level is weaker than that of the mid-gap level. However optically detected ESR has conclusively demonstrated the existence of the $E_{\mathrm{c}}-1.0 \mathrm{eV}$ level in p-GaAs: $\mathrm{Zn} \mathrm{[46].} \mathrm{Thus} \mathrm{the} \mathrm{double} \mathrm{donor} \mathrm{model}$ of figure 3 for the native antisite in as-grown $\mathrm{GaAs}$ appears to be well established, too.

\section{Infrared investigation of persistent $\mathrm{e}^{-}$and $\mathbf{h}^{+}$ carriers, photogenerated from EL2 centres.}

There have been several indications of EL2 related persistent carriers observed in photoconductivity, photo-Hall and photoquenching experiments [56, 57]. Recently, the characteristic infrared absorption of electrons in the conduction band and of holes in the valence band has been used to study the EL2 related photogeneration and photoquenching of persistent carriers in GaAs [32, 58]. This method avoids possible perturbations in the electrical measurements from field gradients or contacts : also, the total carrier concentration is detected by the optical method, free carriers and non-free carriers (e.g. trapped by potential fluctuations in the sample [59]).

For a better understanding of the experiments, we briefly review the knowledge about infrared absorption from free carriers in GaAs. This characteristic infrared absorption was observed and analysed for n-doped GaAs : Se in 1959 [60] and for p-doped GaAs : $\mathrm{Zn}$ in 1962 [61]. The results and the theory have been reviewed [62,63]. For electrons in ndoped GaAs there is scattering by ionized impurities leading to a Drude-like absorption with a $\nu^{-3}$ dependence. In addition there are intra-conductionband transitions (see Fig. 17) from the $\Gamma$ minimum $(q=0)$ to the higher-lying $L$ minima ( $q=$ $1 / 2,1 / 2,1 / 2)$. The onset of this absorption is near $\Delta E=E(L)-E(\Gamma)=0.29 \mathrm{eV}[64]$ with the following frequency dependence [65]

$$
\alpha(h \nu)=c \cdot N_{\mathrm{e}}[h \nu-\Delta E]^{1 / 2}
$$

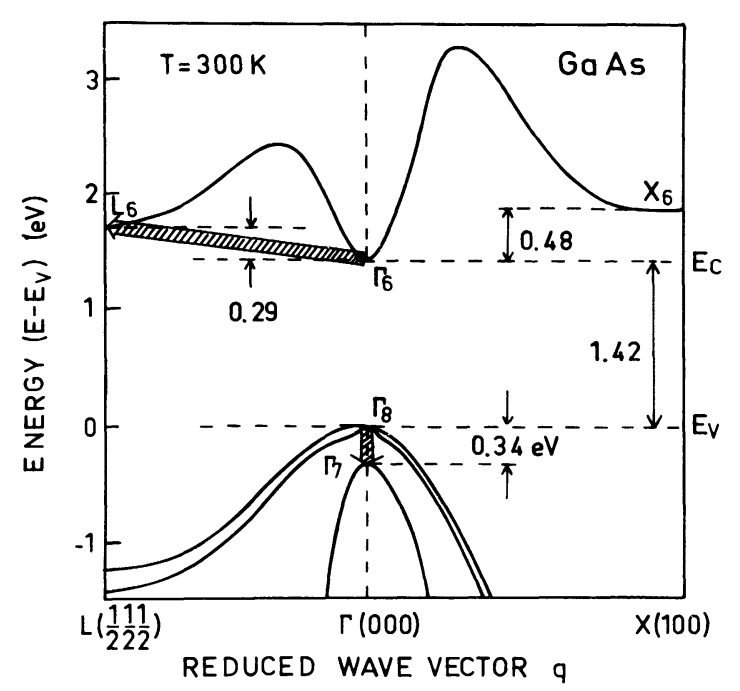

Fig. 17. - Bandstructure of GaAs with relevant energy differences after [64]. The shaded arrows indicate the intraband absorption of electrons and holes. 
where $c$ is a constant and $N_{\mathrm{e}}$ the electron concentration. For $h \nu>3 \Delta E$ the absorption becomes spectrally flat up to the band edge. In undoped GaAs the Drude-like electron absorption is absent.

For holes in p-doped GaAs there is scattering by acoustic lattice phonons, leading to a Drude-like absorption with a $\nu^{-1.7}$ dependence. In addition there are intra-valenceband transitions (see Fig. 17) to the spin-orbit split-off subband. The onset of this absorption is near $0.34 \mathrm{eV}$ with a maximum near $0.40 \mathrm{eV}$ and a subsequent decrease.

It is known from photo-ESR and from photoinduced changes in the EL2 absorption, that the EL2 charge state $\left(\mathrm{D}^{0}\right.$ or $\left.\mathrm{D}^{+}\right)$created during electron and hole-photoionization is stable at low temperatures. Photo generated carriers which neither return to the EL2 centres nor undergo capture at traps [54] and which do not disappear by electron hole recombination should be observable by their infrared absorption. Indeed, electrons [29, 32] and holes [58] were observed recently. In figure $18 \mathrm{a}$ we show the absorption spectrum for electrons, observed in undoped semi-insulating GaAs after complete bleaching of the EL2 absorption. For comparison we show in figure $18 \mathrm{~b}$ the intra conduction band absorption for n-type GaAs : Se [60]. The good agreement, also with the theoretical prediction from equation (5) is evident.

Using the infrared absorption at $0.7 \mathrm{eV}$ as a monitor for the electron concentration transients can

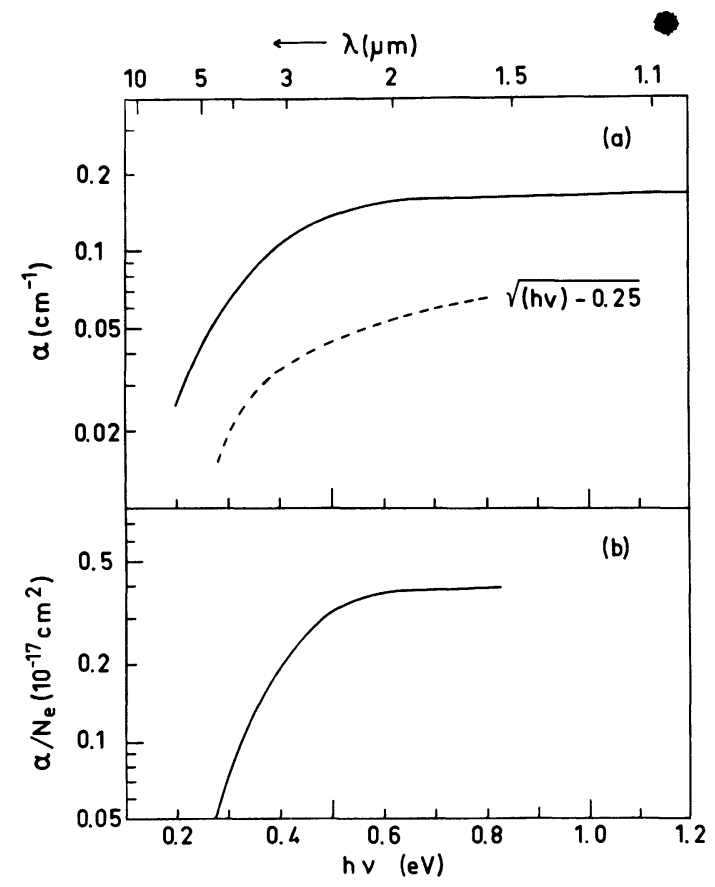

Fig. 18. - (a) Absorption spectrum for persistent n-type carriers in GaAs after complete EL2 bleaching. The broken line is the theoretical energy dependence of equation 5 with $\Delta E=0.25 \mathrm{eV}$ [32]. In (b) the intraband absorption for n-type GaAs: Se $\left(1.3 \times 10^{17} \mathrm{~cm}^{-3}\right)$ is shown [60]. Temperature is $10 \mathrm{~K}$ for (a) and $300 \mathrm{~K}$ for (b). be obtained for different illuminations, as shown in figure 19. Starting from the dark condition, illumination with energy $1.4 \mathrm{eV}$ causes a rapid rise in signal, going through a maximum after three seconds and reaching a steady state after one minute. When the light is switched off, a slow decay of the signal occurs (see Fig. 19a). Next, a condition with higher electron concentration was optically prepared and illumination with energy $1.18 \mathrm{eV}$ causes a decrease in signal (Fig. 19a). The photo generation of persistent electrons during EL2 bleaching is shown in figure $19 \mathrm{~b}$. We can estimate the electron concentration after complete bleaching using figure 18 . The result is $N_{\mathrm{e}}=4 \times 10^{16} \mathrm{~cm}^{-3}$.

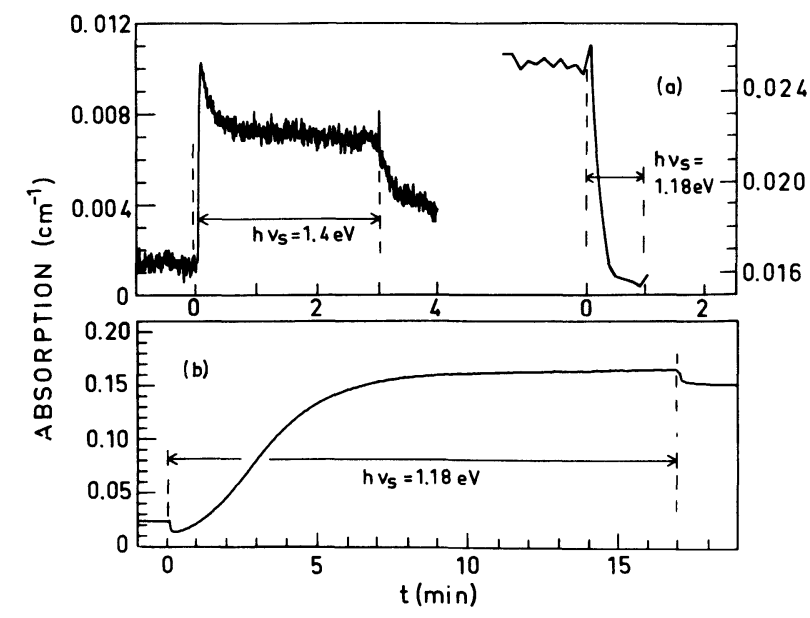

Fig. 19. - Absorption transients for n-type carriers in GaAs observed at $0.7 \mathrm{eV}$ and $T=10 \mathrm{~K}$. In (a) the reversible effects in the short time regime are shown. The transient in (b) is observed during persistent EL2 bleaching. Spectral slitwidth in (a) and (b) is $40 \mathrm{~nm}$. Note that there is an order of magnitude difference between the effects in (a) and (b).

In figure $20 \mathrm{a}$ we show the absorption spectrum for holes, observed in a inhomogeneous and Ga-rich GaAs sample [58]. After cooling in the dark, a small concentration $\left(3 \times 10^{15} \mathrm{~cm}^{-3}\right)$ of holes is detected. After complete bleaching of the EL2 absorption the hole concentration has increased to $8 \times 10^{15} \mathrm{~cm}^{-3}$, i.e. $5 \times 10^{15} \mathrm{~cm}^{-3}$ holes have been photo-generated from $5 \times 10^{15} \mathrm{~cm}^{-3}$ EL2 centres. For comparison we show in figure 20b the Drude-like absorption and the intra-valenceband absorption for p-type GaAs : Zn [61]. Using the infrared (10 $\mu \mathrm{m})$ absorption as a monitor for the hole concentration, absorption transients for illumination with different energies have been recorded. In figure 21 we show typical examples for the short-time and the longtime regime. The interpretation is analogous to that given above for photo-generated electrons.

Confirmation for the involvement of the EL2 centre was obtained by investigating the optical 


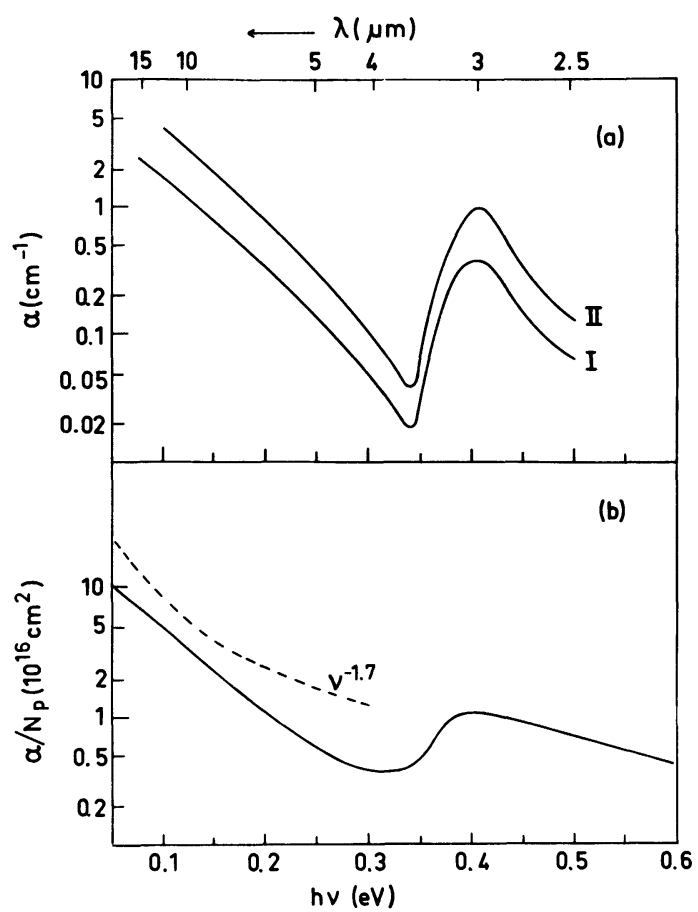

Fig. 20. - (a) Absorption spectrum for persistent p-type carriers in GaAs before (I) and after (II) complete EL2 bleaching [58]. In (b) the absorption for p-type GaAs : $\mathrm{Zn}$ $\left(2.7 \times 10^{17} \mathrm{~cm}^{-3}\right)$ is shown [61]. The broken line indicates the theoretical prediction for scattering by acoustic lattice phonons, while the peak near $0.4 \mathrm{eV}$ is caused by intravalenceband transitions. Temperature is $10 \mathrm{~K}$ for (a) and $84 \mathrm{~K}$ for (b).

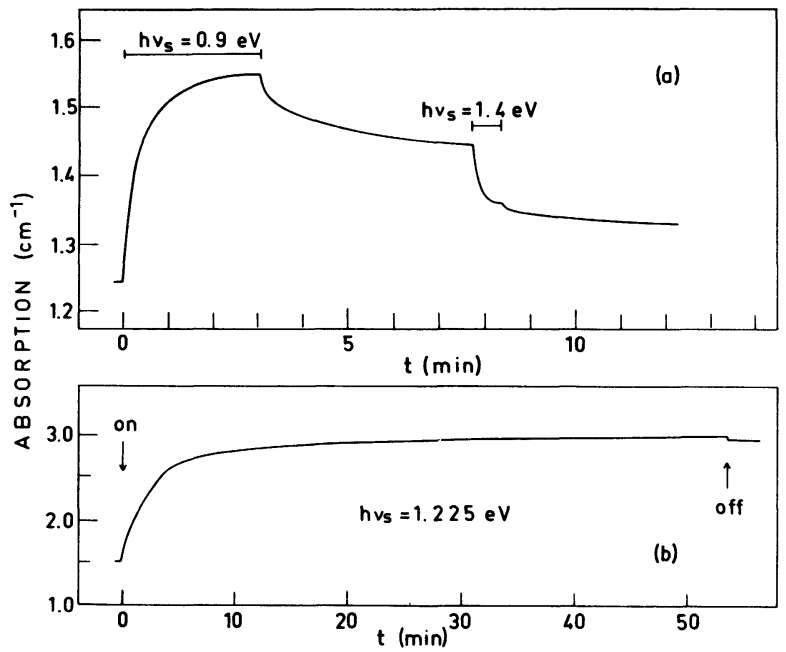

Fig. 21. - Absorption transients for p-type carriers in GaAs observed at $0.12 \mathrm{eV}$ and $T=10 \mathrm{~K}$. In (a) the reversible effects in the short time regime are shown. The transient in (b) is observed during persistent EL2 bleaching. Spectral slit width is $10 \mathrm{~nm}$ in (a) and $40 \mathrm{~nm}$ in (b) [58].

cross-sections for the photo generation of holes. The spectra for $\sigma_{\mathrm{n}}^{0}+\sigma_{\mathrm{p}}^{0}$ and for $\sigma_{*}^{0}$ could be reproduced [58], i.e. the same spectral dependence and the same rate constants were found as for photo-induced changes in the EL2 absorption.

When the temperature is increased, the persistent carriers disappear in a thermally activated process, which is not correlated with the thermal EL2 regeneration from the metastable state (see chapter 3 ). In figure 22 we show absorption coefficients at three photon energies as a function of warm-up temperature following bleaching at $10 \mathrm{~K}$. The hole, electron and EL2 absorptions were monitored at $0.124 \mathrm{eV}$, $0.75 \mathrm{eV}$ and $1.25 \mathrm{eV}$ respectively. This particular sample was evidently inhomogeneous enough to allow coexistence of electrons and holes in spatially separated regions, thus preventing recombination. The $\alpha\left(\mathrm{h}^{+}\right)$and $\alpha\left(\mathrm{e}^{-}\right)$decay curves in figure 22 yield activation energies of $\sim 4$ and $\sim 21 \mathrm{meV}$ respectively [32]. One can speculate that the disappearance of the persistent carriers is related to the thermal release of oppositely charged carriers from shallow donors and acceptors.

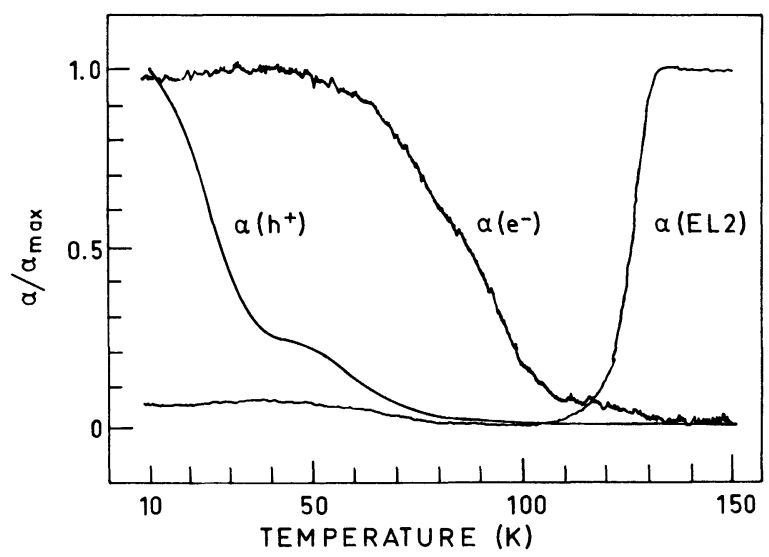

Fig. 22. - Change of absorption during warm-up with $1.7 \mathrm{~K} / \mathrm{min}$ after complete EL2 bleaching at $10 \mathrm{~K}$. The concentration of holes was monitored by their absorption at $0.124 \mathrm{eV}$. The concentration of electrons was monitored by their absorption at $0.75 \mathrm{eV}$. The concentration of EL2 centres in the normal state was monitored by their absorption at $1.25 \mathrm{eV}$ [32].

\section{Summary.}

Secondary below band-gap light induces intensity changes in the EL2 absorption band which are stable at low temperatures. Brief illuminations (a few seconds) produce optically reversible effects which result from changes in the mid-gap level occupation. Long time illumination (a few minutes) in the range $1.0 \mathrm{eV}<h \nu<1.4 \mathrm{eV}$ leads to the persistent quenching of the whole EL2 absorption band. It is related to the transformation of the EL2 defect into its metastable state. The activation energy for thermal regeneration of the EL2 absorption band is distinctly higher in semi-insulating crystals as compared to $n$ type material. The photoresponse of the EL2 absorption band can be consistently explained in terms of 
the EL2 optical cross-sections $\sigma_{\mathrm{n}}^{v}(h \nu), \sigma_{\mathrm{p}}^{0}(h \nu)$ and $\sigma_{*}^{0}(h \nu)$ originally inferred from photocapacitance spectroscopy. The photoresponse of the $\mathrm{As}_{\mathrm{Ga}} \mathrm{ESR}$ signal has been reviewed. As for the EL2 absorption band reversible ESR signal intensity changes occur during short illuminations and the spectral dependencies of the $\mathrm{As}_{\mathrm{Ga}}^{+}$enhancement and quenching reveal close similarities with the EL2 ionization cross-sections $\sigma_{\mathrm{n}}^{0}(h \nu)$ and $\sigma_{\mathrm{p}}^{0}(h \nu)$ respectively. Long time illumination in the range $1.0 \mathrm{eV}<h \nu<$ $1.4 \mathrm{eV}$ leads to nonmonotonic ESR signal transients and a persistent quenching of the $\mathrm{As}_{\mathrm{G} a}^{+}$ESR. The photo-ESR results show that EL2 and the $\mathrm{As}_{\mathrm{Ga}}^{+} \mathrm{ESR}$ have practically the same optical properties. This strongly indicates that one and the same defect is observed in photocapacitance, optical absorption and ESR.

Below band-gap illumination can generate free carriers which do not (or only very slowly) recombine when the light is switched off and which can be monitored via their infrared absorption. This effect is related to the presence of the EL2/As $\mathrm{Aa}_{\mathrm{Ga}}$ defect. For instance the generation band for persistent free holes follows the spectral shape $\sigma_{*}^{0}(h \nu)$ of the quenching band of $\mathrm{EL} 2 / \mathrm{As}_{\mathrm{Ga}}$.

\section{Acknowledgments.}

We thank M. Baeumler, F. Fuchs and J. Windscheif for fruitful cooperation and P. Koidl and J. Schneider for stimulating discussions.

\section{References}

[1] Sturge, M. D., Phys. Rev. 127 (1962) 768.

[2] Wagner, R. J., Krebs, J. J., Stauss, G. H. and White, A. M., Solid State Commun. 36 (1980) 15.

[3] Kaminska, M., Lagowski, J., Parsey, J., Wada, K. and Gatos, H. C., Inst. Phys. Conf. Ser. 63 (1981) 197.

[4] Kaufmann, U. and Schneider, J., Adv. in Electronics and Electron Physics, Vol. 58 (Academic Press, New York) 1982, p. 81.

[5] Lagowski, J., Gatos, H. C., Parsey, J. M., WADA, K., KaminSKa, M. and WaluKiEWICZ, W., Appl. Phys. Lett. 40 (1982) 342.

[6] Elliott, K., Chen, R. T., Greenbaum, S. G. and Wagner, R. J., Appl. Phys. Lett. 44 (1984) 907.

[7] Kaufmann, U., Windscheif, J., BaEumler, M., SCHNEIDER, J. and KöHL, F., Semi-insulating III-V Materials, Eds. D. C. Look and J. S. Blakemore (Shiva Ltd. Nantwich) 1984, p. 246.

[8] Tsukada, N., Kikuta, T. and IshidA, K., Jpn. J. Appl. Phys. 24 (1985) L 689.

[9] Bittepierre, J., Cox, R. T. and Molva, E., Mat. Science Forum, Vol. 10, Ed. H. J. von Bardeleben (Trans. Tech. Publ. Switzerland) 1986, p. 365.

[10] Weber, E. R., Semi-insulating III-V Materials, Eds. D. C. Look and J. S. Blakemore (Shiva Ltd. Nantwich) 1984, p. 296.

[11] Weber, E. R., EnNen, H., Kaufmann, U., WindsCHEIF, J., SCHNEIDER, J. and WOSINSKI, T., J. Appl. Phys. 53 (1982) 6140.

[12] Weber, E. R. and Schneider, J., Physica 116B (1983) 398.

[13] Baeumler, M., KaufmanN, U. and Windscheif, J., Appl. Phys. Lett. 46 (1985) 781.

[14] Baeumler, M., KaufmanN, U. and Windscheif, J., Mat. Res. Soc. Symp. Proc. 46 (1985) 201.

[15] Tsukada, N., Kikuta, T. and Ishida, K., Inst. Phys. Conf. Ser. 79 (1986) 205.

[16] Chantre, A., Vincent, G. and Bois, D., Phys. Rev. B 23 (1981) 5335.
[17] Vincent, G., Bois, D. and Chantre, A., J. Appl. Phys. 53 (1982) 3643.

[18] Martin, G., Semi-insulating III-V Materials, Ed. G. Rees (Shiva Ltd. Orpington) 1980, p. 13.

[19] Morante, J. R., Samitier, J., Perez, A., AlteLarrea, H. and Gourrier, S., J. Appl. Phys. 60 (1986) 1661.

[20] Bois, D. and Vincent, G., J. Physique 38 (1977) L 351 .

[21] Vincent, G. and Bois, D., Solid State Commun. 27 (1978) 431.

[22] Skowronski, M, Lagowski, J. and Gatos, H. C., Phys. Rev. B 32 (1985) 4264.

[23] Mochizuко, Y. and Iкома, T., Semi-insulating III$V$ Materials, Eds. H. Kukimoto and S. Miyazawa (Ohmsha Ltd., Tokyo) 1986, p. 323.

[24] Wosinski, T., Appl. Phys. A 36 (1985) 213.

[25] Lagowski, J., Lin, D. G., Chen, T. P., Skowronski, M. and Gatos, H. C., Appl. Phys. Lett. 47 (1985) 929.

[26] OsaKa, J., Окамото, Н. and Коваyashi, K., Semi-insulating III-V Materials, Eds. H. Kukimoto and S. Miyazawa (Ohmsha Ltd. Tokyo) 1986, p. 421.

[27] Bencherifa, A., Bremond, G., Nouailhat, A., Guillot, G., Guivarch, A. and Regreny, A., Revue Phys. Appl. 22 (1987) 891.

[28] Martin, G. M., Appl. Phys. Lett. 39 (1981) 747.

[29] Dischler, B., Fuchs, F. and Kaufmann, U., Appl. Phys. Lett. 48 (1986) 1282.

[30] Kaminska, M., Skowronski, M., Lagowski, J., Parsey, J. M. and Gatos, H. C., Appl. Phys. Lett. 43 (1983) 302.

[31] Fuchs, F., Dischler, B. and Kaufmann, U., Semiinsulating III-V Materials, Eds. H. Kukimoto and S. Miyazawa (Ohmsha, Tokyo) 1986, p. 329.

[32] Fuchs, F. and Dischler, B., Appl. Phys. Lett. 51 (1987) 679.

[33] Omling, P., Samuelson, L. and Grimmeiss, H. G., Phys. Rev. B 29 (1984) 4534. 
[34] Kuszko, W. and Kaminska, M., Acta Phys. Pol. A 69 (1986) 427.

[35] Weber, E. R. and OMLing, P., Festkörperprobleme (Adv. Sol. State Physics, Vieweg, Braunschweig) XXV (1985) 623.

[36] Mitonneau, A. and Mircea, A., Solid State Commun. 30 (1979) 157.

[37] Trautmann, P., Kaminska, M. and Baranowski, J., Acta Phys. Pol. A 71 (1987) 269.

[38] Von Bardeleben, H. J., Miret, A. and Bourgoin, J., Mat. Sci. Forum, Vol. 10, Ed. H. J. von Bardeleben (Trans. Tech. Publ., Switzerland) 1986, p. 299.

[39] Makram-Ebeid, S., Langlade, P. and Martin, G. M., Semi-insulating III-V Materials, Eds. D. C. Look and J. S. Blakemore (Shiva Ltd., Nantwich) 1984, p. 184.

[40] Hofmann, D. M., Meyer, B. K., Lohse, F. and Spaeth, J. M., Phys. Rev. Lett. 53 (1984) 1187.

[41] Meyer, B. K., HoffMan, D. M., LohSE, F. and Spaeth, J. M., J. Electron. Mater. 14a (1985) 921.

[42] Meyer, B. K. and Spaeth, J. M., J. Phys. C 18 (1985) L 55.

[43] Spaeth, J. M., Hofmann, D. M. and Meyer, B. K., Mat. Res. Soc. Proc. 46 (1985) 185.

[44] Frank, W., Inst. Phys. Conf. Ser. 79 (1986) 217.

[45] Iкомa, T. and Mochizuko, Y., Jpn. J. Appl. Phys. 24 (1985) L 935.

[46] Meyer, B. K., Hofmann, D. M. and Spaeth, J. M., Mat. Sci. Forum, Vol. 10, Ed. H. J. von Bardeleben (Trans. Tech. Publ., Switzerland) 1986, p. 311.

[47] Von Bardeleben, H. J., Stievenard, D., DeresMES, D., Huber, A. and Bourgoin, J. C., Phys. Rev. B 34 (1986) 7192.

[48] Godlewski, M., Phys. Status Solidi A 90 (1985) 11.

[49] In each particular case it must be assured that the threshold is directly related to photoionization of the centre under consideration.
[50] Wosinski, T., Phys. Status Solidi A 60 (1980) K 149.

[51] Bray, R., Solid State Commun. 60 (1986) 867.

[52] BAEUMLER, M., KAUfMANN, U. and WindSCHEIF, J., Semi-insulating III-V Materials, Eds. H. Kukimoto and S. Miyazawa (Ohmsha Ltd. Tokyo) 1986 , p. 361.

[53] Baeumler, M., Kaufmann, U., Windscheif, J. and Wilkening, W., Advanced Materials for Telecommunication, Eds. P. A. Glasow, Y. I. Nissim, J. P. Noblanc and J. Speight (Les Editions Physique) 1986, Vol. XIII, p. 111.

[54] Tsukada, N., Kikuta, T. and Ishida, K., Phys. Rev. B 33 (1986) 8859.

[55] Tsukada, N., Kikuta, T. and Ishida, K., Semiinsulating III-V Materials, Eds. H. Kukimoto and S. Miyazawa (Ohmsha Ltd., Tokyo) 1986, p. 367.

[56] Lin, A. L., Omelianovski, E. and Bube, R. H., J. Appl. Phys. 47 (1976) 1852.

[57] Jiménez, J., Hernandes, P., De SAJA, J. A. and BonnAFÉ, J., Solid State Commun. 55 (1985) 459.

[58] Dischler, B., Fuchs, F. and Kaufmann, U., Proc. Conf. Defects in Semiconductors, Ed. H. J. von Bardeleben (Trans. Tech. Publ., Switzerland) 1986, p. 359.

[59] QueIsser, H. J., Proc. Conf. Physics of Semiconductors, Eds. J. D. Chadi and W. A. Harrison (Springer, New York) 1984, p. 1303.

[60] Spitzer, W. G. and Whelan, J. M., Phys. Rev. 114 (1959) 59.

[61] Braunstein, R. and Kane, E. O., J. Phys. Chem. Solids 23 (1962) 1423.

[62] FAN, H. Y., in Semiconductors and Semimetals, Vol. 3, Eds. R. K. Williardson and A. C. Beer (Academic Press, New York) 1967, p. 405.

[63] Kleinert, P. and Giehler, M., Phys. Status Solidi B 136 (1986) 763.

[64] Blakemore, J. S., J. Appl. Phys. 53 (1982) R 123.

[65] Balslev, I., Phys. Rev. 173 (1968) 762. 